\title{
Correction to: Assessment of cetacean-fishery interactions in the marine food web of the Gulf of Taranto (Northern Ionian Sea, Central Mediterranean Sea)
}

\author{
Roberto Carlucci - Francesca Capezzuto - Giulia Cipriano - Gianfranco D'Onghia • \\ Carmelo Fanizza - Simone Libralato - Rosalia Maglietta • Porzia Maiorano • \\ Letizia Sion · Angelo Tursi · Pasquale Ricci
}

(C) Springer Nature Switzerland AG 2021

\section{Correction to: Rev Fish Biol Fisheries \\ https://doi.org/10.1007/s11160-020-09623-x}

In the original publication of the article, the given name and surname of the authors are inverted in the author's affiliation and in the citation of the article. The correct version of authors' information is provided in this correction.

The correct version of Eq. 1 is provided in this correction. The original article has been corrected.

The original article can be found online at https:// doi.org/10.1007/s11160-020-09623-x.

R. Carlucci · F. Capezzuto $(\bowtie) \cdot$ G. Cipriano ·

G. D’Onghia · P. Maiorano - L. Sion · A. Tursi · P. Ricci Department of Biology, University of Bari, Via Orabona, 4, 70125 Bari, Italy

e-mail: francesca.capezzuto@uniba.it

R. Carlucci - F. Capezzuto - G. Cipriano ·

G. D’Onghia · P. Maiorano · L. Sion · A. Tursi · P. Ricci

CoNISMa, Piazzale Flaminio, 9, 00196 Roma, Italy

C. Fanizza

Jonian Dolphin Conservation, Viale Virgilio, 102-

74121 Taranto, Italy

S. Libralato

OGS, Oceanography Division, ECHO Group, Via Beirut

2/4 (Ex-Sissa building), 34151 Trieste, Italy
$\mathrm{B}_{i} \cdot\left(\frac{\mathrm{P}}{\mathrm{B}}\right)_{i} * \mathrm{EE}_{i}-\sum_{j=1}^{n} B_{j} *\left(\frac{\mathrm{Q}}{\mathrm{B}}\right)_{j} * \mathrm{DC}_{i j}-\mathrm{Y}_{i}-\mathrm{E}_{i}-\mathrm{BA}_{i}=0$

Publisher's Note Springer Nature remains neutral with regard to jurisdictional claims in published maps and institutional affiliations.

R. Maglietta

Institute of Intelligent Industrial Systems and

Technologies for Advanced Manufacturing, National Research Council, Via Amendola, 122 D/O, 70126 Bari, Italy 